\title{
Climate information services, integrated knowledge systems and the 2030 Agenda for Sustainable Development
}

\author{
Fortunate Machingura ${ }^{1,2^{*}}$ D, Admire Nyamwanza ${ }^{3}$, David Hulme ${ }^{1}$ and Elizabeth Stuart ${ }^{2}$
}

\begin{abstract}
This commentary explores the role of climate information services in supporting the achievement of the 2030 Agenda for Sustainable Development. At the centre of the commentary is a discussion of how integrated knowledge systems are critical in the formulation of high quality climate information services towards the successful achievement of the Sustainable Development Goals (SDGs). The paper drives home two major points. Firstly, that a climate service built on integrated knowledge systems will be better positioned to match user needs in terms of skill, scale and lead time. Secondly, that integrating diverse knowledge systems for effective climate information services in the context of the 2030 Agenda for Sustainable Development will present an auspicious platform for 'leaving no one behind' in contributing ideas towards the achievement of the targets outlined under the $17 \mathrm{SDG}$, contributing to the inclusive approach at the centre of Agenda 2030. The commentary also advances the idea that climate information services built upon integrated knowledge systems present opportunities for more adequately addressing the needs of the global poor, including informing agricultural decision-making in rural communities to reduce malnutrition, facilitate disaster preparedness, and tackle human diseases linked to climate change - from cardiovascular deaths and respiratory illnesses, to altered transmission of infectious diseases.
\end{abstract}

Keywords: Climate information services, Knowledge systems, SDGs, Agenda 2030, Leave no one behind

\section{Introduction and background}

\section{What are climate information services?}

Climate information services may be defined as services that provide climate information in a way that assists decision-making by individuals and organisations [1]. Climate information services, therefore, involve the timely production, translation and delivery of useful climate data, information and knowledge for societal decision-making and climate-smart policy and planning [2, 3]. High-quality climate information services (see Table 1) are critical in empowering decision-makers to better manage activities in such areas as agriculture, public health, water resources, energy production, disaster risk reduction and other sectors that are important for national development [4]. Climate information services are meant to provide the science-based and user-specific information for managing risks and exploiting opportunities created by climate variability and change, thereby helping society to become more resilient in coping with the increasing impacts of climate change [5]. As Krauss and von Storch [6] (p: 217) aptly put it, "ideally, the main tasks of climate information services are to provide climate information for stakeholders, education for the general public (and) to design decision support tools and technical assistance". Vaughan and Dessai [7] note that, to date, climate services have primarily focused on three areas, which are: (a) forecasting forthcoming seasons to inform decision-making (b) projecting long-term trends to guide policy-making and strategic planning and (c) monitoring and predicting climate-related hazards for disaster risk management.

\section{Climate information services and the imperative to leave no-one behind \\ The 2030 agenda's ambition to 'leave no one behind', put the worst off first and help the most vulnerable and}

\footnotetext{
* Correspondence: fmachingura@gmail.com

'Global Development Institute, University of Manchester, Oxford Road, Manchester M139PL, England

2Overseas Development Institute, 203 Blackfriars Road, London SE1 8NJ England

Full list of author information is available at the end of the article
}

(0) The Author(s). 2018, corrected publication November 2018. Open Access This article is distributed under the terms of the Creative Commons Attribution 4.0 International License (http://creativecommons.org/licenses/by/4.0/), which permits

unrestricted use, distribution, and reproduction in any medium, provided you give appropriate credit to the original author(s) and the source, provide a link to the Creative Commons license, and indicate if changes were made. The Creative Commons Public Domain Dedication waiver (http://creativecommons.org/publicdomain/zero/1.0/) applies to the data made available in this article, unless otherwise stated. 
Table 1 High and poor quality climate information services

In the context of this discussion, high quality climate services are characterised by climate information products and dissemination channels that are perceived by targeted users to be legitimate, credible and salient, and hence usable. Credibility refers to trustworthiness, reliability and dependability of the climate service. A legitimate climate service is one that is transparent, open and free from political persuasion or bias, whilst a salient climate service is one that is context specific and sensitive to users' demands vis-à-vis spatial, ecological, temporal and administrative scales [18]. A high quality climate service is one that is also equally accessible to and easy to use for all targeted users regardless of class, literacy levels or language. On the other hand, a poor quality climate service is one that is not perceived to be credible, salient and legitimate by all the targeted users, and that is not easily accessible to and user-friendly for all social groups.

extremely poor to reach their full potential is not just a foundational equity principle to ending poverty in all its forms everywhere for every person [8]. It should also be seen as a commitment to a climate-smart development narrative which places emphasis on inclusive stewardship of climate information services, particularly among the most vulnerable and marginalised social groups [9]. Improved climate information services are essential for the management of climatic opportunity and risk in climate-sensitive sectors such as water, agriculture, disaster risk reduction and health. Importantly, they help to harness climate opportunities towards increasing productivity and to manage uncertainty that limits better decision-making among the poor vis-à-vis climate risk management and adaptation practice [9]. Climate information services availability and application remain weakest in countries that need them most - low-income, climate-vulnerable developing and least developed countries (LDCs). These countries, owing to their geographic and socio-economic circumstances represent, today, the most vulnerable with increased exposure to disasters and heightened risk of death and are least capable of coping with climate-related extreme events such as storms, droughts, and floods [10]. At the centre of this narrative is the weak integration of indigenous, cultural and historical knowledge systems that adequately address the interlinked challenges of climate risks [10]. There is, therefore, an increased danger of reversing the equity gains and the progress achieved so far threatening the anticipated SDG outcomes, particularly in the context of 'leaving no-one-behind'. Poor climate information services (see Table 1) can expose vulnerable groups to new risks and worsen pre-existing vulnerabilities and drivers of marginalisation resulting in deeper marginalisation, poverty and inequalities [10].

Limited access to responsive climate information services hinders poor communities' capacities to prevent, cope, respond to and recover from climate shocks and stresses [10]. Thus, disasters tend to have very significant impacts on the lives of poor people especially in terms of loss of life and asset or livelihood depletion. Some social groups experiencing extreme deprivation and poverty reside in remote zones that are often neglected due to a lack of connectivity and inaccessibility and are thus particularly vulnerable to the effects of climate stresses [4]. Such social groups often lack sufficient finances and support to move to safer zones or to access much-needed climate information services.

Further, climate information services that are less responsive to needs can themselves exacerbate inequality and increase poverty and exclusion. For instance, climate information services mostly accessed via the internet and foreign languages (such as English) may provide information to elites who can access the internet, and who own mobile devices and read English. If the benefits of an intervention are captured by elites, and mostly men, the intervention may increase the marginalisation and relative poverty of those not reached, such as women in remote rural areas thereby raising inequalities [9]. As Lemos and Dilling [11] argue, unequal distribution of knowledge can insulate decision-making, facilitate elite capture of resources, and alienate disenfranchised groups. Moreover, the constellations of multiple disadvantages that extreme poor and excluded groups face predisposes them to be even more vulnerable to external shocks, or suffer from the adverse impacts of poorly managed climate information services and less integrated climate knowledge systems, making the 'leave no-one behind' agenda more unlikely to be achieved.

\section{Climate information services and agenda 2030}

Drawing on the 2017 white paper on 'the contribution of the Global Framework for Climate Services (GFCS) to the 2030 agenda for SDGs,' [4] four discernible factors are critical if climate information services are to contribute to the 2030 agenda's commitment to leave no-one behind. Firstly, there is a need for a performance tracking system of climate information whose goal is to assess the current state of the climate system (including land, ocean and atmosphere), and uses this to discern the average future climate (see also reference [12]). However, (and secondly), to understand and assess the performance of the climate service system, data needs archiving and stewardship. This means that data repositories and archives must not only appraise and acquire data but also make data available for research by archiving and migrating it to new technologies. These acts of stewardship suggest the conversion of data to standard and emerging electronic formats - a process that is vital to preserving and enhancing the global climate information systems. Thirdly and relatedly, this climate information must be readily accessible, be of improved quality for analysis of climatic events and attributing factors, including likely impacts on humans and ecosystems. Finally, climate information services need to build in 
them, a resilience factor at which point they can predict near-term climate change from seasons to decades while timely and correctly disseminating this data and suggesting means for people to prevent, cope, adapt and transform in the wake of externalities of climate variability [4].

Most of these factors require knowledge of relationships among environmental and social impact variables, understanding and coping with uncertainties and helping users understand the information. Similarly, achieving the SDGs and meeting the commitment to leave no-one behind in the Agenda 2030 means that countries must have access to the climate information required to implement these SDGs. This climate information system must, however, also be complemented by multiple and integrated links between basic research to applied research and transfer to operations of new technology, methods and products. A critical enquiry into the analysis of the determinants of social and ecosystem vulnerability, resilience and adaptive capacity is equally imminent. The starting point, however, which is also the object of this commentary, is to underpin the role of climate information services in supporting the achievement of SDGs.

This commentary examines the role of climate information services in supporting the achievement of the 2030 Agenda for Sustainable Development. A discussion on what characterises high quality climate information services (see Table 1) is central in this commentary. This is important as the characteristic of a climate service (which includes the quality of the information that underpins it) determines whether it will succeed or fail in delivering its intended goal [2]. In that regard, the commentary explores and shows how integrated knowledge systems are critical in formulating high quality climate information services towards the achievement of SDGs. The commentary is organised around three main sections. Following this introduction is an exploration of the specific role of climate information services in the achievement of SDGs. This is followed by a discussion on how integrated knowledge systems are at the centre of effective climate information services. The final section provides conclusions and policy recommendations.

\section{Climate information services and the sustainable development goals}

The majority of the 17 SDGs identified under Agenda 2030 and many of their 169 targets and activities are weather and climate sensitive [4]. The providers of climate information services will therefore have a critical role in assisting countries to implement the 2030 Agenda and the SDGs [3]. As highlighted in Table 2, most of the 17 SDGs' success can be directly linked to accessible and accurate climate information services. As the World Meteorological Organisation (WMO) [4] articulates, there is a risk-based element to the achievement of most of the goals and therefore access to high quality, fit-for-purpose climate information services will greatly reduce the risks associated with the achievement of the SDGs and their related targets.

Delivering the vision of SDGs, particularly in LDCs, is therefore intrinsically linked to high quality and robust information and products related to current and future climates [13]. Besides the direct role of climate information services in the achievement of the majority of SDGs as highlighted in Table 2, climate information will also form the basis of important baseline information vis-à-vis monitoring and evaluating the achievements of the 2030 Agenda for Sustainable Development. For example, as the WMO [4] notes, in compiling the achievements of the goals and activities towards 2030, the prevailing climate information will provide context in terms of many of the relevant targets.

\section{Integrated knowledge systems for effective climate information services}

As noted in the introduction, because climate information services are critical in the delivery of the new global framework for sustainable development, it is imperative to explore what characterises an effective climate service. One key aspect of effective climate information services that can assist their roles in making Agenda 2030 a success is integrating the diverse knowledge systems that inform these services in generating and delivering climate information and related products to different users. This is because a lack of useful and understandable climate information has regularly been pointed out as a huge problem in climate information services discourse [1], A major source of this problem is the lack of effective and adequate engagement between climate service information producers and end-users - who often operate in and subscribe to different knowledge systems.

\section{Understanding knowledge systems}

Knowledge systems may be conceptualised as comprising of agents, practices and institutions that organise the production, transfer and use of knowledge [14]. Scientific knowledge has been the major basis of mainstream climate information services though indigenous technical knowledge and practitioner knowledge have also influenced the generation and communication of climate information in communities around the world. Whilst scientific knowledge refers to systematised knowledge that can be replicated and validated by recognised experts (usually through a series of logical and empirical methods), indigenous knowledge refers to the place-based experiential knowledge of a community accumulated over generations of living in a particular environment $[6,14]$. Practitioner knowledge, on the other hand, is knowledge, in this case, informing climate information, held and 
Table 2 Role of climate information services in the achievement of selected SDGs

\begin{tabular}{l} 
Goals \\
\hline Goal 1 - End poverty in all its forms everywhere \\
Goal 2 - End hunger, achieve food security and improved nutrition and \\
promote sustainable agriculture
\end{tabular}

Goal 3 - Ensure healthy lives and promote well-being for all at all ages

Goal 6 - Ensure availability and sustainable management of water and sanitation for all

Goal 7 - Ensure access to affordable, reliable, sustainable and modern energy for all

Goal 9 - Build resilient infrastructure, promote inclusive and sustainable industrialisation and foster innovation

Goal 11 - Make cities and human settlements inclusive, safe, resilient and sustainable

Goal 13 - Take urgent action to combat climate change and its impacts

Goal 14 - Conserve and sustainably use the oceans, seas and resources for sustainable development

Goal 15 - Protect, restore and promote sustainable use of terrestrial ecosystems, sustainably manage forests, combat desertification, and halt and reverse land degradation and halt biodiversity loss

Role of climate information services

- Climate forecasts (both seasonal and long-term) will assist farmers, fishers and herders to make better and informed decisions by anticipating and reducing their exposure and vulnerability to climate-related impacts leading to increased agricultural productivity and food trade, improved livelihoods and better land-use practices.

- Climate forecasts and other advisories will also help food insecure communities to safeguard and enhance crop-yields and ultimately improve food security

- Early warning systems for such extreme weather events as floods and droughts will decrease morbidity and mortality from diseases related to these events by supporting timely and targeted health interventions

- Seasonal downscaled forecasts and analyses on the hydrological cycle will improve local and regional allocation of water resources and enhance the wise use of water across different sectors

- Provision of climate information around energy infrastructure investments and the promotion of sustainable energy development will be key in ensuring affordable, reliable and sustainable energy

- Climate monitoring and long-term projections will be critical in informing infrastructural projects, city-planning, climate-proofing of buildings and construction of dams and sea-walls in coastal and other vulnerable areas

- Climate monitoring and early warning systems in urban areas can reduce the effects of extreme weather events such as floods as well as support city land-zoning and the construction of appropriate infrastructure towards climate-resilient cities

- Early warning systems for extreme weather events will improve the preparedness of people to respond to the effects of these events as well as help to increase their resilience to climate-related hazards

- Climate information and forecast around such issues as ocean acidity levels and/or nutrient overload can help protect marine ecosystems and improve biodiversity leading to economic gains and improved livelihoods

- Medium to long-term climate projections can assist with information on future habitat and ecosystem changes which can promote and advise conservation and restoration activities. This climate information may also assist policy-makers to develop proactive and sustainable national drought management policies.

Source: UN Department of Economic and Social Affairs, [5]

utilised by practitioners such as resource managers, government bureaucrats and players in non-governmental, developmental and civil society organisations (Intasave: Bridging knowledge systems for effective, sustained and widespread adaptation in semi-arid regions of Africa and Asia, Unpublished).

\section{A new kind of knowledge system}

In moving towards the successful implementation of Agenda 2030 for Sustainable Development, a new kind of an inclusive knowledge system that actively manages the boundary between expertise and decision-making, enforces trust and legitimacy of actors and products on both sides of the boundary, and jointly produces outputs, will be required as the basis for effective climate information services [6]. This new knowledge system should be a hybrid or integration of the knowledge systems highlighted in the previous sub-section, as capturing the claims and perspectives of different climate knowledge holders will be central in increasing the salience, legitimacy, acceptability and credibility of information, products and dissemination channels leading to improved usability. As Tulloch and colleagues [15] note and as already been highlighted in the introduction section, a key, crosscutting and fundamental aspiration of the 2030 Agenda and the SDGs is 'leaving no one behind'. This means those who have been previously excluded, marginally included or overlooked by progress must now be fully included [8]. Results needed for the 'leaving no one behind' agenda are as much about inclusion in progress as about delivery of a service or benefit [9]. Nowhere is the challenge of 'leaving no one behind' more salient than in knowledge production. The observation and assessments of weather and climate information by indigenous people and local communities, for example, have largely remained detached from mainstream climate information services, in part due to the formal requirements of scientific documentation and 
peer-review analysis [9, 10]. As Lourenco et al. [16] posit, discussions about climate services thus far have been largely dominated by a supply-side perspective and framed from a standpoint of climate observations and modelling. The new kind of an integrated knowledge system advanced in this commentary however ensures that hitherto marginalised groups' voices are listened to and that the engagement between providers and users of climate information is strengthened, as illustrated in Table 3. The goal is to have climate services that are based on and informed by a close collaboration of information providers, boundary organisations and different levels of users [17].

The majority of the Sustainable Development Goals include the 'for all' phrase ultimately reflecting the need for an inclusive approach in executing the activities and achieving the targets underpinning the goals [15]. In essence therefore, recognising the importance and centrality of diverse knowledge systems in formulating effective climate information services for the achievement of the SDGs contributes to the inclusive aspiration of Agenda 2030. Whilst the idea of integrating knowledge systems is not necessarily new, identifying effective ways of achieving that integration has remained a challenge that climate information services science should deal with, and addressing this challenge has become even more urgent in the context of the goals and wide-ranging targets and activities underpinning Agenda 2030. Policy recommendations towards dealing with this challenge are suggested in the conclusion section.

It is imperative to note, however, as underscored by Kirchhoff and colleagues [18] that integrating knowledge

Table 3 Climate information services in the Canadian Arctic

Scientific weather information has been widely distributed and used in the Canadian Arctic over the years, however it is limited in several ways. For instance, the weather can change very quickly in the region yet quick updates to forecasts are not always available. The scientific information distributed also lacks detailed forecasts on wind, yet abrupt shifts in wind direction, winds that pick up without notice, and an increase in south/southeast winds are all common and recurring weather concerns which impact on livelihoods in the region. Scientific weather information around storm surges has also not been very reliable since this depends on accurate information on wind characteristics such as speed and direction. A number of indigenous communities in the region have however relied on local observations and explanations around such phenomena as clouds, wind, the sky, wildlife behaviour, direction of the tide-flow, snow drifts and direction of currents to correctly predict various weather and climatic changes in wind direction, temperature, storm surges and precipitation. This indigenous knowledge is however underrepresented in general climate information services and climate change research in the region. As advanced in this paper, one of the ways of ensuring the successful implementation of the SDGs in regions like the Canadian Arctic would be to take steps towards creating platforms on which scientific and local weather and climate information are integrated and distributed in similar ways. This calls for the recognition and appreciation of hitherto marginalised voices of indigenous communities in forecasting weather and climatic changes, towards creating fit-for-purpose, credible and relevant climate information services in the region.

Source: Pennesi et al. [20] systems vis-à-vis climate information services has its difficulties. These difficulties include the huge efforts and time required in reconciling diverse and sometimes conflicting values, worldviews and epistemologies of all stakeholders as well as a high level of human resources required to undertake that task in practice. In addition, such intrinsic factors characteristic of (scientific) climate information as lack of skill in predictions at certain timescales and challenges in the provision of information at certain spatial scales, limit the utility of climate information services, whether or not integration of knowledge systems informing these services takes place. Furthermore, as Lemos and Dilling [11] rightly point out, climate information tools are largely communicated and disseminated using the language of probabilities, which is not easy to comprehend for non-scientists as non-scientists, generally, do not think probabilistically neither do they interpret probabilities easily. Notwithstanding the foregoing, climate information services that are based on and informed by integrated knowledge systems potentially provide more opportunities for the realisation of climate information, products and dissemination channels that are more credible, salient and legitimate.

\section{Conclusions and policy recommendations}

The widespread influence of climate on the majority of Agenda 2030's Sustainable Development Goals means that the demand for accessible, locally-customised and accurate climate information services will increase with each passing year. In supporting the achievement of the Sustainable Development Goals, improved climate information services will ensure that information users can make climate-smart decisions and that information dissemination is done in a way that guarantees effective practical action [4]. One major way of improving climate information services towards achieving Agenda 2030 targets discussed is integrating the knowledge systems base of climate information services. We make the following conclusions with respect to the issues raised in this commentary and policy recommendations vis-à-vis effective climate information services and Agenda 2030.

\section{Conclusion 1}

Climate information services are central to achieving the success of Sustainable Development Goals and the demand for climate information services vis-à-vis Agenda 2030 will continue to grow in the years ahead.

Recommendations: establish and support institutions that spearhead critical climate information services research, advisory and tailored products for government, private and public sector players

- Investments are needed particularly in most LDCs and SIDS to build the requisite technical and 
scientific capabilities such as observation networks, training of research personnel and establishment of effective early warning systems [1]

- This will ensure the availability of, and access to high quality weather and climate information tailored to address the decision-making requirements of various users

\section{Conclusion 2}

Informing decision-making in the context of Agenda 2030 will require new ways of thinking and, for climate information services, this will mean actively integrating the diverse knowledge systems which underpin them so as to close the persistent gap between climate information production and use.

Recommendations: develop and promote inclusive nonhierarchical feedback and engagement mechanisms and forums that will enable providers and users (especially socially excluded and marginalised groups) of climate information to work together in co-designing and co-generating climate information products and dissemination channels

- Actively explore ways of bringing together different framings, representations and legitimations of climate information and dissemination channels emanating from different knowledge systems

- Expand access to climate information services through the use of a combination of methods commonly utilised by holders of different knowledge systems, including information and communication technologies (e.g. call services, SMS, voice recordings, rural radio), boundary organisations working in communities (such as non-governmental organisations, community based organisations and agricultural extension services), and face-to-face dialogues between climate information providers and users [19]

- Engage inclusive, iterative, interactive and flexible mechanisms of knowledge exchange between players subscribing to different knowledge systems, including climate scientists, resource users and practitioners, towards building mutual respect, trust, climate information products and dissemination channels that are acknowledged, accepted, accessible and used across knowledge boundaries

- Promote the new information products and dissemination channels coming out of these multi-scale and interdisciplinary forums on multisited novel platforms, including in art and politics

\section{Conclusion 3}

More research is needed to understand climate information user needs and decision-making processes in different contexts towards coming up with high quality, accessible and accurate climate information services which will adequately support the activities and targets of Agenda 2030.

Recommendations: promote and support the carrying out of more in-depth ethnographic studies and the use of participatory methodologies aimed at exploring different climate information user needs and decision-making processes in different contexts

- Facilitate efficient coordination between academic institutions, climate research centres and meteorological agencies towards the production of demand-led climate knowledge, information and products [13]

- Undertake demand-driven research that seeks to explore the kinds of climate information that are useful in different contexts and for different groups (especially the excluded and disadvantaged) and examine how that information should be constructed, translated and communicated.

- Strengthen the evidence base of the actual value of produced climate information services through rigorous monitoring and evaluation of the services in different contexts using a combination of contextappropriate qualitative and quantitative approaches and based on a theory of change that appropriately captures the input-output-outcome-impact chain of the services.

Abbreviations

GFCS: Global Framework for Climate Services; LDCs: Least Developed Countries; SDGs: Sustainable Development Goals; SIDS: Small Island Developing States; WMO: World Meteorological Organisation

\section{Funding}

The writing of this paper has been possible with the support from the United Kingdom's Economic and Social Research Council, grant number ES/ P010245/1 under the Global Challenges Research Fund.

Availability of data and materials

The datasets analysed during the current study are available in the Citations of and include DOls and full URLs where applicable.

Authors' contributions

FM led and was the major contributor in writing the manuscript. All authors, equally contributed in writing, reading and approving the final manuscript.

Ethics approval and consent to participate

Non Applicable

Consent for publication

Non Applicable

Competing interests

The authors declare that they have no competing interests.

\section{Publisher's Note}

Springer Nature remains neutral with regard to jurisdictional claims in published maps and institutional affiliations. 


\section{Author details}

Global Development Institute, University of Manchester, Oxford Road, Manchester M139PL, England. ${ }^{2}$ Overseas Development Institute, 203 Blackfriars Road, London SE1 8NJ, England. ${ }^{3}$ Human Sciences Research Council, Economic Performance and Development Unit, Merchant House Building, 116-118 Buitengrancht Street, Cape Town, South Africa.

Received: 16 December 2017 Accepted: 6 September 2018

\section{Published online: 25 October 2018}

\section{References}

1. Lugen M. Climate services for development in Burkina Faso: Institutions, use and needs for national planning. KLIMOS Working Paper No. 13. KLIMOSACROPOLIS. Brussels. Belgium. 2017. Available: https:/ees.kuleuven.be/klimos/ papers/wp13_climate_services_in_burkina_faso.pdf. Accessed 3 Sept 2017.

2. Vaughan C, Buja L, Kruczkiewicz A, Goddard L. Identifying research priorities to advance climate services. Climate Services. 2016:4:65-74.

3. Vaughan C, Dessai S, Hewitt C. Surveying climate services: what can we learn from a bird's eye view? Weather, Climate and Society. 2018;10:373-95.

4. World Meteorological Organization. White paper on the contribution of the global framework for climate services to transforming our world: the 2030 agenda for SustainableDevelopment (Agenda 2030). Geneva: World Meteorological Organization (WMO); 2017.

5. United Nations Department of Economic and Social Affairs. Global Framework for Climate Services. 2016. Available: https://sustainabledevelopment.un.org/index. php?page=view\&type=30022\&nr=123\&menu=3170. [Accessed 3 Sept 2017].

6. Krauss W, von Storch H. Post-normal practices between regional climate services and local knowledge. Nat Cult. 2012;7(2):213-30.

7. Vaughan C, Dessai S. Climate services for society: origins, institutional arrangements and design elements for an evaluation framework. Wiley Interdiscip Rev Clim Chang. 2014;5:587-603.

8. Stuart E, Samman E. Defining 'leave no one behind. 2017. Available: https:// www.odi.org/sites/odi.org.uk/files/resource-documents/11809.pdf. [Accessed 27 Nov 2017].

9. Mittal N, Perera N, Korkeala O. Learning Materials: Leaving No-one Behind in the Climate and Environment context. 2016. Available: https://assets. publishing.service.gov.uk/media/58483145e5274a130300005f/EOD_LNB_ Learning_Materials_FINAL.pdf.

10. United Nations International Strategy for Disaster Reduction. Poverty \& Death: Disaster mortality 1996-2015. 2016. Available: http://www.unisdr.org/ files/50589_creddisastermortalityallfinalpdf.pdf. [Accessed 27 Nov 2017].

11. Lemos MC, Dilling L. Equity in forecasting climate: can science save the world's poor? Sci Public Policy. 2007;34:109-16.

12. Trenberth $\mathrm{KE}$, Marquis $\mathrm{M}$, Zebiak $\mathrm{S}$. The vital need for a climate information system. Nat Clim Chang. 2016;6:1057-9.

13. ClimDev-Africa. Africa, sustainable development and climate change; the role of climate research. In: Climate Research for Sustainable Development. Available: https:/www.uneca.org/sites/default/files/images/climate research_for_sustainable_development_en.pdf. [Accessed 12 Sept 2017].

14. Cornell S, Berkhout F, Willemijn T, Tàbara DJ, Jäger J, Chabay I, de Wit B. Opening up knowledge systems for better responses to global environmental change. Environ Sci Pol. 2013;28:60-70.

15. Tulloch O, Machingura F, Melamed C. Health, migration and the 2030 agenda for sustainable development. Bern: Swiss Agency for Development and Cooperation; 2016.

16. Lourenco TC, Swart R, Goosen H, Street R. The rise of demand-driven climate services. Nat Clim Chang. 2016;6:13-4.

17. Harjane A. Servitizing climate science - institutional analysis of climate services discourse and its implications. Glob Environ Chang. 2017:46:1-16.

18. Kirchhoff CJ, Lemos MC, Dessai S. Actionable knowledge for environmental decision-making: broadening the usability of climate science. Annu Rev Environ Resour. 2013;38:393-41.

19. Tall A, Hansen J, Jay A, Campbell B, Kinyangi J, Aggarwal PK, Zougmore R. Scaling up climate services for farmers: Mission possible. Climate change, agriculture and food security (CCAFS), CCAFS Report No 13; 2014:1-44.

20. Pennesi K, Arokium J, McBean G. Integrating local and scientific weather knowledge as a strategy for adaptation in the Arctic. Mitig Adapt Strateg Glob Chang. 2012;17:897-922.

\section{Ready to submit your research? Choose BMC and benefit from:}

- fast, convenient online submission

- thorough peer review by experienced researchers in your field

- rapid publication on acceptance

- support for research data, including large and complex data types

- gold Open Access which fosters wider collaboration and increased citations

- maximum visibility for your research: over $100 \mathrm{M}$ website views per year

At $\mathrm{BMC}$, research is always in progress.

Learn more biomedcentral.com/submissions 